\title{
Composição elementar e caracterização da fração lipídica de seis cultivares de caupi
}

\author{
Rolando E. R. Castellón ${ }^{1}$, Francisca M. M. C. de Araújo², Márcio V. Ramos ${ }^{3}$ \\ Manoel Andrade Neto ${ }^{4}$, Francisco R. Freire Filho ${ }^{5}$, Thalles B. Grangeiro ${ }^{3}$ \& Benildo S. Cavada ${ }^{3}$ \\ 1 Doutorando do Curso de Fitotecnia da UFC. Campus do Pici, CP 6033, CEP 60.451-970, Fortaleza, CE (Foto) \\ 2 Departamento de Ciências Naturais, Universidade Regional do Rio Grande do Norte, Mossoró, RN \\ ${ }^{3}$ Laboratório de Moléculas Biologicamente Ativas, UFC. Campus do Pici, CP 6033, CEP 60.451-970, Fortaleza, CE \\ ${ }^{4}$ Laboratório de Produtos Naturais, UFC \\ ${ }^{5}$ Embrapa Meio Norte. Av. Duque de Caxias 5650, Buenos Aires, CP 01, CEP 64006-220, Teresina, PI
}

Protocolo $103-2 / 7 / 2001$ - Aprovado em 30/1/2003

\begin{abstract}
Resumo: A composição bioquímica elementar de sementes de seis cultivares de feijão de corda (Vigna unguiculata) foi determinada e a fração lipídica de cada cultivar, caracterizada. Os resultados sugerem que todas as farinhas de semente compartilham composição bioquímica similar, embora as cultivares $\mathrm{Br}-14$ e $\mathrm{CE}-315$ difiram das $\mathrm{Br}-9$ e $\mathrm{Br}-17$ no teor de umidade. As frações lipídicas purificadas foram caracterizadas quanto ao teor e tipos de ácidos graxos presentes. A cultivar $\mathrm{Br}-17$ possui alto conteúdo de ácido palmítico $(58,2 \%)$ e o menor conteúdo de ácido linoléico $(6,4 \%)$ enquanto a Vita 7 apresenta alto conteúdo de ácido linoléico $(21,8 \%)$ e relativamente baixo conteúdo de ácido palmítico (41\%) em uma base comparativa. Os ácidos graxos pentacosanóico e eicosanóico representam a fração lipídica menor e o primeiro não ocorre em CE-315. Os resultados sugerem que diferentes cultivares obtidas por melhoramento genético podem apresentar diferenças quantitativas e qualitativas na composição bioquímica; assim, diferenças na capacidade germinativa, resistência a predadores no campo de plantio e no armazenamento, poderiam estar relacionadas à inibição ou estímulo da expressão de genes codificadores da síntese de moléculas relevantes, que refletem diferenças de composição, como demonstrado neste trabalho.
\end{abstract}

Palavras-chave: ácidos graxos, cromatografia, feijão de corda, Vigna unguiculata L. Walp

\section{Biochemical composition and characterization of lipid fraction of six cowpea cultivars}

\begin{abstract}
The biochemical composition of the seeds of six bean - Vigna unguiculata (Walp) cultivars was determined and the lipid fraction of each of these cultivars was characterized. The results suggest that all analyzed seed flours share similar biochemical composition, although the cultivars $\mathrm{Br}-14$ and $\mathrm{CE}-315$ differ in relation to $\mathrm{Br}-9$ and $\mathrm{Br}-17$ in water content. The purified fatty acid fractions were characterized according to their lipid content. The cultivar $\mathrm{Br}-17$ possesses high content of palmitic acid (58.2\%) and low content of linoleic acid $(6.4 \%)$ while Vita 7 possesses high contents of linoleic acid $(21.8 \%)$ and relatively low content of palmitic acid $(41 \%)$ on a comparative basis. Pentacosanoic and eicosanoic acids represent the minor fraction of lipids and the former does not occur in CE-315. The results suggest that different cultivars obtained by genetic combination may present relevant differences in their biochemical composition. Thus, differences in germination capacity, resistance to predators in the field or storage house may be related to over expression or inhibition of genes encoding synthesis of relevant molecules which refleet difference in composition as demonstrated in this study.
\end{abstract}

Key words: chromatography, fatty acids, cowpea beans, Vigna unguiculata L. Walp

\section{INTRODUÇÃO}

Caupi é uma das principais culturas alimentares do Nordeste. Sua importância tem sido demonstrada pelo IBGE, que aponta um consumo "per capita" anual de $16 \mathrm{~kg}$ (Araújo, 1988; Maia, 1996). Embora esta leguminosa seja alvo de estudos que visam melhorar a produtividade, resistência a doenças e pragas, salinidade e estresses hídrico, as lavouras nordestinas continuam a enfrentar queda de produção anual.
As estratégias de combate à praga deste feijão, o inseto Callosobruchus maculatus, e de aumento da produtividade, têm sido desenvolvidas através de melhoramento genético de sementes (Fantunla \& Badaru, 1983; Pinto, 1998); entretanto, os dados estatísticos apontam que novas cultivares, inicialmente mais resistentes e produtivas, perdem essas características a médio prazo, sendo necessário a produção de novas cultivares alternativas (Pinto, 1998). Assim, novas sementes têm constantemente sido ofertadas ao produtor, mas 
esta estratégia, há tempos utilizada pela pesquisa agronômica, tem sido gradativamente associada ou substituída por técnicas de biologia molecular que visam à obtenção de cultivares transgênicas mais aptas às adversidades ambientais das regiões de plantio. Por outro lado, os estudos bioquímicos dessas sementes de plantas domesticadas e a produção contínua de novas cultivares obtidas através de técnicas de melhoramento genético têm demonstrado importantes mudanças na composição química das sementes e mesmo na expressão de proteínas envolvidas na defesa da planta (Chrispeels \& Raikhel, 1991). No caso da cultura de sementes de Phaseolus vulgaris, uma proteína, denominada arcelina, expressa nas sementes de cultivares selvagens, não é observada em sementes de plantas cultivadas (Schoonhoven et al., 1983; Osborn et al., 1988); deste modo, o cruzamento de plantas induzido, buscando aperfeiçoar algumas características, em detrimento de outras, poderia explicar, ao menos em parte, a perda de produtividade de novas cultivares, após várias gerações das sementes produzidas.

De acordo com esses resultados, seria interessante avaliarse aspectos bioquímicos de cada nova cultivar obtida, quer por melhoramento genético, quer por engenharia genética, para se obter dados sobre o comportamento da semente quanto à variação do teor protéico, fração lipídica, digestibilidade e outros parâmetros bioquímicos.

Em vista desta discussão, o objetivo do trabalho foi avaliar a composição bioquímica e a fração lipídica de seis cultivares comerciais de feijão caupi.

\section{MATERIAL E MÉTODOS}

Foram utilizadas sementes de seis cultivares de feijão-decorda (Vigna unguiculta (L) Walp), comerciais: Br-14 Mulato, CE-315, Br-17 Gurguéia, Br-9 Longá, CNC-0434 e Vita 7. As sementes foram obtidas da Estação Experimental da EMBRAPA Meio Norte, Teresina, Estado do Piauí, e destegumentadas manualmente, seguidas de trituração em moinho elétrico, para obtenção de farinha fina. As farinhas assim obtidas foram armazenadas adequadamente e estocadas em câmara a $12{ }^{\circ} \mathrm{C}$.

\section{Determinação de umidade}

Para a determinação do teor de umidade das farinhas, amostras contendo $200 \mathrm{mg}$ de farinha de cada cultivar foram colocadas em pesa-filtros previamente tarados. Os conjuntos, com três repetições, foram colocados em estufa a $110^{\circ} \mathrm{C}$ por $24 \mathrm{~h}$, após o que foram mantidos em um dessecador contendo sílica-gel, até atingir a temperatura ambiente, sendo então pesados. O procedimento de pesagem foi repetido até que um valor constante de peso fosse obtido para cada amostra analisada; o teor de umidade foi calculado pela diferença entre o peso inicial e final das amostras e expresso em percentagem.

\section{Determinação de cinzas}

A determinação do teor de cinzas nas farinhas foi obtida utilizando-se cadinhos de porcelana previamente tarados após $24 \mathrm{~h}$ em estufa a $100{ }^{\circ} \mathrm{C}$; cada cadinho, contendo $500 \mathrm{mg}$ de amostra, foi colocado em uma mufla a $650{ }^{\circ} \mathrm{C}$ durante $4 \mathrm{~h}$, até a completa incineração de todo o material orgânico; em seguida, foram transferidos para um dessecador contendo sílica-gel, onde permaneceram até atingir a temperatura ambiente; enfim, os cadinhos contendo as amostras incineradas foram então pesados e o teor de cinzas calculado pela relação entre o peso do resíduo e o peso inicial da amostra, sendo o resultado expresso em percentagem.

\section{Determinação de nitrogênio total}

O teor de nitrogênio total das farinhas analisadas foi determinado após a digestão das amostras com ácido sulfúrico, segundo o método de Baethgen \& Alley (1989).

\section{Determinação de lipídeos totais}

A determinação de lipídeos totais nas farinhas das sementes das cultivares foi feita segundo a técnica descrita por Triebold (1946), utilizando-se o éter de petróleo como solvente extrator.

Amostras de 2,0 g de cada cultivar foram submetidas a extração lipídica com três lavagens sucessivas com éter de petróleo, por duas horas, com agitações ocasionais. O extrato resultante da reunião dos sobrenadantes das três lavagens foi evaporado em evaporador rotatório, sob pressão reduzida obtendo-se, assim, os extratos lipídicos. O teor de lipídeos foi então calculado pela relação entre o peso do extrato etéreo e o peso inicial da amostra, expresso em percentagem.

\section{Determinação de lipídeos saponificáveis e insaponificáveis}

Uma alíquota do extrato lipídico de cada cultivar (contendo entre $100 \mathrm{e} 150 \mathrm{mg}$ ) foi dissolvida em aproximadamente $15 \mathrm{~mL}$ de etanol e acondicionada em um balão de $125 \mathrm{~mL}$, contendo 5 $\mathrm{mL}$ de $\mathrm{KOH}$ a $50 \%$. A mistura foi deixada em repouso por uma hora, após o que foi concentrada à metade de seu volume e extraída com éter em funil de separação. A partir da evaporação do éter, foi obtida a fração insaponificável. A fase aquosa etanólica foi acidificada com ácido clorídrico concentrado (37\%) até atingir o pH 3,0 e extraída com éter. A fração etérea foi submetida a evaporação sob pressão reduzida, fornecendo o material saponificável (ácidos graxos).

Para a obtenção dos ésteres metílicos foram adicionados $10 \mathrm{~mL}$ de metanol e 5 gotas de ácido clorídrico concentrado. A mistura foi levada a refluxo durante 15 min e, após tratada com $20 \mathrm{~mL}$ de água destilada e $5 \mathrm{~mL}$ de éter, foi colocada novamente em refluxo por mais $15 \mathrm{~min}$, transferida para um funil de separação e extraída com éter de petróleo. Após evaporação do éter foram obtidos os ésteres metílicos.

A análise dos ésteres metílicos foi realizada através de cromatografia em fase gasosa acoplada à espectrometria de massas com coluna $5 \%$ fenil-metil-silicone em sílica fundida $(25 \mathrm{~m} \mathrm{x} 0,20$ $\mathrm{mm}, 0,20 \mathrm{~mm}$; programação de temperatura: iniciando em $50^{\circ} \mathrm{C}$ com aumento em gradiente linear de $4^{\circ} \mathrm{C} / \mathrm{min}$ até atingir $180^{\circ} \mathrm{C}$; seguido de incrementos de $20^{\circ} \mathrm{C} / \mathrm{min}$ a partir de $180^{\circ} \mathrm{C}$ até atingir a temperatura final de $250^{\circ} \mathrm{C}$ ). A identificação dos ésteres metílicos foi realizada com o auxílio de um software desenvolvido por Alencar et al. (1984) seguindo-se o procedimento clássico da literatura, através de padrões de espectrometria de massa.

\section{Análise estatística}

Os dados de análise elementar foram comparados quanto às suas médias, através do teste de Tukey ao nível de significância de $1 \%$. Os dados de carboidratos foram estimados por diferença. Os dados de lipídeos, apresentados nas Tabelas 2 e 3 , referem-se a valores médios dos cromatogramas e foram obtidos como descrito anteriormente (Alencar et al., 1984). 


\section{RESULTADOS E DISCUSSÃO}

Sementes de seis cultivares de Vigna unguiculata foram avaliadas comparativamente quanto à análise elementar e caracterização da fração lipídica.

As cultivares Br-14 mulato e CE-315 apresentaram teor de umidade similar, porém inferior àquele das cultivares BR-17 e Br-9, enquanto a CNC-0434 e Vita-7 apresentaram valores intermediários (Tabela 1). Os valores de umidade de Br-17 e Br9 são considerados elevados quando comparados àqueles de outras cultivares de Vigna unguiculata (Chaves et al., 1952; Rodrigues, 1986); entretanto, a Br-17 destacou-se das demais cultivares, segundo a análise estatística empregada. $\mathrm{O}$ teor de proteína, obtido através da determinação de nitrogênio nas farinhas, é bastante similar em todas as cultivares e constitui a segunda maior fração elementar, inferior apenas à fração de carboidratos. Neste parâmetro, três grupos distintos foram formados, destacando-se a Br-17.

O teor de lipídeos totais representou a menor fração dentre aquelas analisadas nas sementes das seis cultivares (Tabela 1), porém, esses valores correspondem aos observados em outras cultivares de caupi e mesmo para outras espécies de leguminosas da tribo Phaseoleae (Hsieh et al., 1992). A despeito da homogeneidade observada, a cultivar $\mathrm{Br}-9$ foi a que mais se diferenciou das demais, apresentando o menor valor para lipídeos totais. O teor de cinzas variou entre 2,3 (cultivares $\mathrm{Br}$ 9 e Br-17) a 3,2\% (cultivar CE-315). Esses valores se situam em uma faixa ligeiramente inferior à encontrada para outras cultivares de caupi (Carvalho \& Monteiro, 1969; Araújo et al., 1975; Rodrigues, 1986). Quantitativamente, a principal fração das farinhas foi a de carboidratos e, quanto a este parâmetro, as cultivares mostraram-se homogêneas.
Os resultados da análise da fração lipídica das sementes de seis cultivares estão na Tabela 2. As cultivares CNC-0434 e Br9 apresentam considerável diferença na fração saponificável. Quanto à fração lipídica insaponificável, os valores determinados variam entre as amostras, sendo que a $\mathrm{Br}-17$ e a Vita-7 representam as cultivares de maior e menor teor, respectivamente, enquanto as demais apresentaram teor intermediário de lipídeos saponificáveis. A análise detalhada desses lipídeos, quanto ao tipo e à quantidade dos ácidos graxos, é apresentada na Tabela 3. As cultivares apresentaram o ácido graxo saturado hexadecanoato (ácido palmítico, 16 C) como o ácido graxo mais abundante, porém tais resultados são contrários àqueles mencionados por Sales \& Rodriguez (1988) que encontraram, para outras cultivares de caupi, predominância de ácidos graxos insaturados entre os lipídeos saponificáveis; em contrapartida, esses resultados estão concordantes com os encontrados para seis espécies de leguminosas do gênero Acacia, em que a porção lipídica saponificável apresenta o ácido palmítico (saturado) como o mais abundante (Santi, 1995). Estudo semelhante, realizado com farinhas de sementes de sete espécies do gênero Mimosa (Leguminosae, Mimosoideae), mostrou que, em geral, predomina o ácido graxo saturado hexadecanoato, com exceção da

Tabela 2. Teores de lipídeos saponificáveis e insaponificáveis em sementes de seis cultivares de caupi

\begin{tabular}{lccc}
\hline \multirow{2}{*}{ Cultivares } & \multicolumn{3}{c}{ Percentagem de Lipídeos } \\
\cline { 2 - 4 } & Totais & Insaponificáveis & Saponificáveis \\
\hline Br-14 & 1,42 & 11,48 & 57,75 \\
Br-9 & 1,23 & 10,00 & 60,95 \\
Br-17 & 1,64 & 13,73 & 48,97 \\
CNC-0434 & 1,64 & 9,25 & 47,80 \\
Vita 7 & 1,49 & 8,97 & 52,10 \\
CE-315 & 1,71 & 11,56 & 50,90 \\
\hline
\end{tabular}

Tabela 1. Análise elementar* de sementes de seis cultivares de caupi

\begin{tabular}{|c|c|c|c|c|c|c|}
\hline \multirow{2}{*}{ Parâmetros (\%) } & \multicolumn{6}{|c|}{ Cultivares } \\
\hline & $\mathrm{Br}-14$ & Br-9 & Br-17 & CNC-0434 & Vita-7 & CE-315 \\
\hline Umidade & $11,4 \pm 0,1 \mathrm{c}$ & $14,3 \pm 0,4 b$ & $15,9 \pm 0,1 \mathrm{a}$ & $13,7 \pm 0,3 b$ & $13,9 \pm 0,3 b$ & $11,6 \pm 0,5 c$ \\
\hline Lipídeos totais & $1,4 \pm 0,1 \mathrm{ab}$ & $1,2 \pm 0,1 b$ & $1,6 \pm 0,1 \mathrm{a}$ & $1,6 \pm 0,2 \mathrm{a}$ & $1,5 \pm 0,1 \mathrm{ab}$ & $1,7 \pm 0,2 \mathrm{a}$ \\
\hline Cinzas & $2,5 \pm 0,1 b c$ & $2,3 \pm 0,2 \mathrm{c}$ & $2,3 \pm 0,0 \mathrm{c}$ & $2,8 \pm 0,2 \mathrm{ab}$ & $2,5 \pm 0,2 b c$ & $3,2 \pm 0,0 \mathrm{a}$ \\
\hline Carboidratos $^{2}$ & 74,5 & 74,5 & 71,4 & 73,9 & 73,5 & 74,2 \\
\hline
\end{tabular}

Nitrogênio total (Kjeldahl) x 6,25

Obtido por diferença

Médias acompanhadas por letras iguais na mesma linha não são significativamente diferentes ao nível de $1 \%$, segundo o teste de Tukey

Tabela 3. Percentagem* de ácidos graxos em sementes de seis cultivares de caupi

\begin{tabular}{|c|c|c|c|c|c|c|c|c|}
\hline \multicolumn{3}{|c|}{ Parâmetros } & \multicolumn{6}{|c|}{ Percentagem $^{* *}$} \\
\hline Metil éster & Ácido graxo & Tipo & $\mathrm{Br}-14$ & $\mathrm{Br}-9$ & $\mathrm{Br}-17$ & CE-315 & Vita 7 & CNC-0434 \\
\hline Hexadecanoato & Palmítico & $(\mathrm{C} 16: 0)$ & 49,2 & 48,3 & 58,2 & 52,0 & 41,5 & 47,31 \\
\hline 9,12 Octadecadienoato & Linoléico & $(\mathrm{C} 18: 2[9,12])$ & 11,5 & 7,5 & 6,4 & 12,6 & 21,8 & 12,83 \\
\hline 9-Octadecanoato & Oléico & $(\mathrm{C} 18: 1[9])$ & 13,1 & 13,2 & 9,7 & 13,3 & 12,5 & 9,87 \\
\hline Octadecanoato & Esteárico & $(\mathrm{C} 18: 0)$ & 11,9 & 11,1 & 11,1 & 11,2 & 10,0 & 12,51 \\
\hline Eicosanoato & Eicosanóico & $(\mathrm{C} 20: 0)$ & 4,1 & 3,6 & 4,4 & 4,0 & 3,1 & 5,38 \\
\hline Docosanoato & Docosanóico & $(\mathrm{C} 22: 0)$ & 6,0 & 7,7 & 6,9 & 6,9 & 6,2 & 9,09 \\
\hline Pentacosanoato & Pentacosanóico & $(\mathrm{C} 25: 0)$ & 4,5 & 3,7 & 3,7 & - & 2,7 & 3,02 \\
\hline Não identificado & & & - & 5,0 & - & - & 2,3 & - \\
\hline
\end{tabular}

" No cálculo das percentagens foram eliminados os contaminantes

* A identificação foi feita por comparação de índices de Kovats e espectros de massas 
espécie Mimosa pigra, que apresenta o ácido graxo insaturado cis-9,12-octadecenóico (ácido linolêico) e da espécie Mimosa acutistipula, cujo ácido graxo mais abundante é o insaturado cis-9-octadecenóico (ácido olêico) (Gadelha, 1995). Os outros ácidos graxos saturados encontrados nas cultivares estudadas, foram os ácidos Esteárico, Eicosanóico, Docosanóico e Pentacosanóico, com exceção da cultivar CE-315, que não apresentou o ácido Pentacosanóico.

Comparando-se apenas o teor do ácido graxo essencial linoléico nas farinhas estudadas, observam-se consideráveis diferenças, principalmente na farinha da semente da cultivar Vita 7, quando comparado com os valores determinados para as demais cultivares, em especial a cultivar $\mathrm{Br}-17$, cujo teor do ácido linoléico representa próximo de $1 / 3$ do valor encontrado para Vita-7 (Tabela 3). Embora esta magnitude, analisada separadamente, indique diferença bioquímica importante entre duas cultivares de uma mesma espécie, não se constitui apenas em uma diferença quantitativa. Esta característica fenotípica deve ser resultado da expressão de diferenças nos genótipos, que se refletem na indução de síntese diferenciada do conjunto de enzimas relacionadas com a biossíntese deste ácido, nas duas cultivares; além disto, a capacidade de estocagem deste produto metabólico poderia igualmente ser diferenciada entre diferentes cultivares, desde que, neste estudo, apenas a fração lipídica foi investigada em detalhes e o número de cultivares analisadas não representa uma amostra significativa das cultivares utilizadas na agricultura. Um estudo bem mais completo das frações de proteína e carboidratos, além da fração lipídica, deveria ser conduzido para melhor caracterizar as diferenças bioquímicas entre cultivares antigas, pouco melhoradas, e cultivares modernas, que sofreram pressão de seleção para produtividade e outros caracteres. Considerando-se, ainda, que o caupi é constituinte básico de proteína e carboidratos na dieta de parte da população brasileira, a cultivar ideal deveria apresentar o maior teor de proteína e carboidrato possível.

\section{CONCLUSÕES}

1. As diferenças quantitativas e qualitativas encontradas nas principais moléculas constituintes nas sementes das seis cultivares de caupí sugerem que o processo de melhoramento genético induziu mudanças substanciais no padrão bioquímico das mesmas. Destaca-se a cultivar Br-17 ao apresentar a melhor performance do ponto de vista nutricional.

2. Investigações deste tipo podem ser extendidas a outras partes vegetativas para avaliar-se tanto o grau de diferenciação alcançado pelas novas cultivares como para direcionar programas específicos de melhoramento nesta espécie.

\section{AGRADECIMENTOS}

Este trabalho foi desenvolvido com o apoio financeiro do CNPq, FUNCAP, PADCT, FINEP, BNB, IFS (MVR) e BioTools Ecological Foundation órgãos aos quais são direcionados os agradecimentos. T.B. Grangeiro e B.S. Cavada agradecem ao CNPq pela concessão das bolsas.

\section{LITERATURA CITADA}

Alencar, J.W.; Craveiro, A.A.; Matos, F.J.A. Kovats indices as preselection routine in mass spectra library search of volatiles. Journal of Natural Products, Columbus, v.47, p.890892, 1984.

Araújo, J.P.; Watt, E.E. O caupi no Brasil. Brasília: IITA/ EMBRAPA, 1988. 722p.

Araújo, T.M.V.C.; Lago, E.S.; Bion, F.M. Valor nutritivo das misturas: feijão macaçar integral + farinha de mandioca, e feijão mulatinho integral + farinhas de mandioca, suplementadas com diferentes níveis de metionina. Revista Brasileira de Pesquisa Médica e Biológica, Campinas, v.8, p.143-7, 1975.

Baethgen, W.E.; Alley, M.M. A manual colorimetric procedure for measuring ammonium nitrogen in soil and plant Kjeldahl digest. Soil Science Plant Analysis, North Carolina, v.20, n.9/10, p.961-969, 1989.

Carvalho, J.P.; Monteiro, E.S. Feijão macaçar na alimentação de frangos para corte. Recife: Centro de Pesquisas Agronômicas de Pernambuco, 1969. 5p. Boletim Técnico, 94-A

Chaves, N.; Teodosio, N.R.; Matos, JR. As proteínas do feijão macassar na nutrição. Revista Brasileira de Medicina, São Paulo, v.9, p.605-7, 1952.

Chrispeels, M.J.; Raikhel, N.V. Lectins, lectins genes and their role in plant defence. In: Vand Driessche, E.; Kilpatrick, D.; Bog-Hansen, T.C. (eds.) St. Louis: Lectins Reviews, 1991. Cap. 6, 183-194.

Fatunla, T.; Badaru, K. Inheritance of resistence to cowpea weevil (Callosobrucus maculatus, Fabr.). Journal of Agricultural Science, Cambridge, v.101, p.423-426, 1983.

Gadelha, A.C.A. Estudo quimiotaxonômico de constituintes de sementes de representantes do taxon Mimosa (Leguminosae-Mimosoideae) pertencentes a três diferentes secções. Fortaleza: UFC, 1995. 107p. Dissertação Mestrado

Hsieh, H.M.; Pomeranz, Y.; Swanson, B.G. Composition, cooking time, and maturation of Azuki (Vigna angularis) and common beans (Phaseolus vulgaris). American Association of Cereal Chemistry, Minesota, v.69, n.3, p. 244-248, 1992.

Maia, F.M.M. Composição e caracterização nutricional de três cultivares de Vigna unguiculata: EPACE 11, Olho de Ovelha e IPA-206. Fortaleza: UFC, 1996. 87p. Dissertação Mestrado

Osborn, T.C.; Alexander, D.C.; Samuel, S.M.S.; Cardona, C.; Frederick, A.B. Insecticidal activity and lectin homology of arcelin seed protein. Science, Washington, v.240, p.207-210, 1988.

Pinto, V.P.T. Digestibilidade in vitro e in vivo das frações albumina e globulina de oito cultivares de caupi (Vigna ungluiculata (L.) Walp.). Fortaleza: UFC, 1998. 88p. Dissertação Mestrado

Rodrigues, M.A.C. Formulação de produtos alimentícios à base de misturas de feijão caupi (Vigna unguiculata (L.) Walp) e sorgo granífero (Sorgum bicolor (L.) Moench). Fortaleza: UFC, 1986. 109p. Dissertação Mestrado 
Sales, M.G.; Rodriguez, M.A. Consumo, qualidade nutricional e métodos de preparo do caupi. In: Araújo, J.P.O.; Watt, E.E.; (eds.). O caupi no Brasil. Brasília: IITA/EMBRAPA, 1988. Cap. 24, p.697-721.

Santi, T. Estudo quimiotaxonômico em sementes de espécies do gênero Acacia (Leguminosae). Fortaleza: UFC, 1995. 95p. Dissertação Mestrado
Schoonhoven, A.V.; Cardona, C.; Valor, J. Resistance to the bean weevil and the Mexican bean weevil (Coleoptera: Bruchidae) in non cultivated common bean accessions. Journal of Economic Entomology, Maryland, v.76, n.6, p.1255-1259, 1983.

Triebold, H.O. Quantitative analysis with applications to agricultural and food products. New York: D. van Nostrand Co., p.331, 1946. 